\title{
Job-related Musculoskeletal Disorders in Bus Drivers of Lahore, Pakistan
}

\author{
Muhammad Wajahat Aslam ${ }^{1}$, Fahad Tanveer ${ }^{2}$, Hafiz Sheraz Arshad ${ }^{3}$ \\ ${ }^{1}$ Physical Therapist, Azra Naheed Medical College, Department of Physical Therapy, Main Raiwind Road,Lahore \\ ${ }^{2}$ Lecturer, Azra Naheed Medical College, Department of Physical Therapy, Main Raiwind Road,Lahore
}

${ }^{3}$ Head of Department/Assistant Professor, Azra Naheed Medical College, Department of Physical Therapy, Main Raiwind Road,Lahore

\begin{abstract}
The purpose of this study is to find out frequency of job-related musculoskeletal disorders in bus drivers of Lahore, Pakistan. Methodology: it was an observational, descriptive study. A total of 273 individuals were selected in this study to collect data by use of standardized Nordic questionnaire. Result: A total of 273 subjects were involved, from where $i$ have come to know shoulder and upper back region disorders were more frequent in bus drivers of Lahore, Pakistan and least frequent site is wrist/hands region. Conclusion: this present study concludes that there is high frequency of job related musculoskeletal disorders common in bus drivers.Most commonly effected regions were shoulder and upper back and least common was wrist/hands region.
\end{abstract}

Keywords: Job related musculoskeletal disorders, Bus drivers, shoulder pain, upper back pain

\section{Introduction}

\subsection{Overview}

Job-related musculoskeletal disorders are reported frequently above all is low back pain in many working group's causative to a big financial failure to persons and for society too. Trained drivers are prone in emerging such harms due to long time sitting and vibratory exposure. Many studies have been done in drivers from lot of types of vehicles for example, automobile, intercity buses, jeeps etc. Various type of vehicles causes stress on body, as the driver's seat, control mechanisms and vibration generated might be different. There are many cases of job-related musculoskeletal problems had been reported in past in various studies conducted in united states and European professional bus drivers, however, very much less studies had done in Asia and almost no study done in Pakistan at all. Along with various types of musculoskeletal disorders, may be, drivers of buses have low back pain which is widely reported in past studies. In previous studies, the researchers also reported, bus drivers were more prone to lower back pain; drivers of buses had the maximum chances of lower back pain amongst the three work-related groups. Past researches also tells us that male drivers of trucks had four times more prone to lumber disc hernia if compare with deskbound workers group. [1]

Experienced bus drivers have more threat of musculoskeletal problems and low back pain and disc prolapse. Etiologic factors that have been suggested are the whiplash problems and full body vibrations in association with lifting and unlifting the vehicle. Risks of spinal injuries were more in bus drivers as compare to truck drivers. May be the risk of the injury of the lower limb and the spine became more due to continuous jerks and large forces transfer through spine and legs. [2]

The most important and common health problems are lower back pain and job related musculoskeletal disorders which are not only affecting occupational workers but also affecting common people. Frequency of lower back pain is associated with different types of occupations. In many establishing countries, possible factors, only studied recently, of work related low back pain and not well developed rules or policy were made in past on full body vibration and hand transmitted vibrations. That's why, a study should be conducted in whole country along with all drivers, especially drivers of buses will be the consideration of government for calculating the lower back pain and other musculoskeletal disorders occurrence, possibilities finding out and for reduction in injuries because of lower back pain and other musculoskeletal problems by developing interventions as bus drivers are at high risk of accidents. [3]

Mostly after long stay of rest these mechanically demanding activities are regularly conceded out, the most tiring of muscles and ligaments of lower back is thought to be because of deficiency of attentiveness. Unhygienic food and lack of exercise and other factors like smoking can causes vulnerability to lower back pain in truck drivers. At later stage due to lack of body nutrition the lack of spinal disc nutrition occurs, due to which susceptibility to mechanical stress takes place. May be harmful daily routine factors are present in truck drivers in greater amount as compared with common residents. [4]

Millions of people in whole world are affected by Low back pain and other job related musculoskeletal problems. These problems are affecting not only the person who are directly experiencing this but also affects the whole community. In reality, it has been studied, that in the rising world lower back pain is one of the most common causes for sick leave. Many factors are known, those are significant work related stressors and are causative of low back problems and musculoskeletal disorders, other than this, the postural tension and continuous experience of full body vibration are the two most important factors. It is to be considered that the threat becomes more complex, when Manual materials 


\section{International Journal of Science and Research (IJSR) ISSN (Online): 2319-7064 \\ Index Copernicus Value (2013): 6.14 | Impact Factor (2015): 6.391}

handling is also experienced by the driver along with postural stress and full body vibrations. [5]

This study is use full to find out frequency of musculoskeletal disorders in different buses drivers, delegated model of apparatus were used for evaluation of Vibratory component and locomotives were also used by different drivers' batches in past studies. In conclusion the possible threats are calculating for musculoskeletal problems by find out the relationship between full body vibration, objective stress component and psychological and community factors. [6]

The objective of this study is to find out frequency of jobrelated musculoskeletal disorders amongst drivers of buses in Lahore Pakistan. The association of different job related harmful factors like as long sitting, anthropometric components, shaking effect, steering wheel \& gear management will be discovered by calculating musculoskeletal disorders. Call for medical cure and Effect of a variety of uneasiness on occupations daily life were also interrogated, because these components point out severe musculoskeletal injuries. [7]

As this study is going to be held first time in Pakistan, so I will find out frequency of job-related musculoskeletal disorders in Lahore, Pakistan, and this study will be helpful in future for making of preventive measurements, that will reduce job- related musculoskeletal disorders in professional bus drivers of Lahore, Pakistan.

Many studies have been conducted in past ,here are, some studies ," This study was conducted by Anker Jensen, finntuchsen and linda in 2007 to find out prevalence of locomotive problems or diseases in male drivers of truck and skill full other vehical drivers, they concluded that risk of locomotive problems are present in approximately all type of professional drivers, however, different job situation and nature of automobile are related with diverse effects on locomotors organization and health. [2]

The research was done by KrauseN,Ragland DR and fisher JM in 1997,to investigate the relationship of back and neck pain with social and psychological, occupational factors in community bus drivers, the results concluded that social and psychological, occupational factors have great role in causing back and neck pain. [8]

This study was conducted by kazuhitoyokoyama and shamsulbahrimohdtamrin et.al. In May, 2007, to find out relationship of lower back pain and risk components in professional drivers of automobiles in Malaysia, concluded that negative moods of Malaysian drivers is a large causative factor for danger of lower back pain as compared with substantial components, the research find out that, experiencing full body vibratory motion is less as compare with past researches and not related with lower back pain. Uncomfortable sitting position or posture is also not related with lower back pain because drivers personalized straight sitting and incline postures. Occupational situations, like as experience, disclosure to full body vibration, adjustment of tyres and steering all are related to lower back pain and other job related factors like extra work, accidents in the past also increase the risk of low back pain, this study concluded that not only one however, many factors may be act as risk factors of lower back pain in drivers. [3]

This study was conducted by Neil J Mansfield and Martin J $\mathrm{M}$ robb, to find out musculoskeletal disorders in experienced truck drivers, the conclusion, point out the relationship of musculoskeletal disorders and driving a truck. The result shows that the drivers who are driving on long routes have less occurrences of musculoskeletal problems; this result shows us that some other factors are also contributing in musculoskeletal problems. Uneasiness of seat and manual handling are related with, musculoskeletal disorders, and interventions were given to reduce musculoskeletal problems in drivers. [4]

The study was done by Olanrewaju O, Marianne Magnusson and Okuniribido in 2006, to check the relationship between full body vibration, manually material handling and postural demands in bus operators and lower back pain, and concluded that, The bus drivers of the city spent 60 Percent of their work time in driving buses, and they experience uncomfortable stress, jerks, and forced vibration. The most prevalent disorder is low back pain in city bus drivers. The preventive measures which are concluded in this study are breaks in work time for drivers and use of buses with auto transmissions instead of manual transmissions may be helpful to reduce incidence of low back pain in drivers. [5]

This study was conducted by authors: Massimo bovenzi and liviarondiba et al, in 2006, to investigate lower back pain in skillful operators of automobiles. This is a cross-sectional study that tells us that professional bus driving raises the danger of job-related lower back pain. The study shows that lower back pain risk largely increases due to full body vibration ,mechanical stress and due to driving and minor relation of increase in low back pain due to social and psychological components. [6]

The study was conducted by Grace P.Y.Szeto and peggoLam in 2007, in hongkong,to find out prevalence of occupation related musculoskeletal problems in drivers of buses, this study concluded that the prevalence rate of occupation related musculoskeletal problems is more within hongkong. [7]

The study was conducted by OyewoleO.O. andakinpelu A.O. et al,. in may 2011, to study in Ibadan, Nigeria about occurrence of musculoskeletal pain and behavior related to health amongst professional drivers. And this study concluded that the occurrence of musculoskeletal pains in professional drivers is very high and the very frequently reported pain is low back pain in drivers, as the drivers experience increases, the musculoskeletal pain also increases. The driver uses drugs without prescription from doctor and also uses other health care therapies. This is requirement of time to program classes to educate the drivers that how they can avoid the problems and risk too, about musculoskeletal pain.[9]

This study is conducted by Jiu-Chiuan Chen, Wen-Ruey Chang et al, in 2005, to find out the association of use of back hold up and seat leaning in lower back pain among 


\section{International Journal of Science and Research (IJSR) \\ ISSN (Online): 2319-7064}

Index Copernicus Value (2013): 6.14 | Impact Factor (2015): 6.391

drivers of taxi. This study concluded that reliable results came with the use of these mechanical supports among taxi drivers in low back pain as they know by past studies, but the need to do prospective study is necessary. [10]

The study was conducted by Ashok jadhao, sandeepgunjal and amodborle to investigate musculoskeletal disorders in central India bus drivers. The study concluded that the most frequently reported musculoskeletal problem is back pain and then after it most frequent is joint pain, then low back pain. The musculoskeletal problems are mostly associated with driving work out,age and total time of daily driving, and increases with the increase in respective above factors, problems are more in drivers with BMI 30 per kilogram $/ \mathrm{m} 2$. [11]

\subsection{Objective}

To find out frequency of job related musculoskeletal disorders in bus drivers of Lahore Pakistan

\subsection{Rationale}

This study is helpful in reduction of job related musculoskeletal disorders, which will improve the health of bus drivers of Lahore, Pakistan.

\subsection{Operational definitions}

\subsubsection{Nordic questionnaire}

This is a tool, which is used to evaluate musculoskeletal symptoms, and the reliability has been checked out by test retest system ,tells us that answers ,that are non-distinguishable fluctuate from zero to twenty-three percent, validity test tells us that answers that are non-distinguishable, changed between zero to twenty percent. [12]

\subsection{Materials and methods}

\subsubsection{Study design}

Observational study

\subsubsection{Setting}

Different bus terminals of Lahore

\subsubsection{Study population}

Bus drivers of Lahore

\subsubsection{Duration of study}

The duration of study was 3 months.

\subsubsection{Sample size}

Data was collected from 273 bus drivers from the total estimated 20,000 population of bus drivers in Lahore, Pakistan .The sample size was calculated by following formula:

$$
\begin{aligned}
x & =\mathrm{Z}\left({ }^{c} / 100\right)^{2} \mathrm{r}(100-\mathrm{r}) \\
n & =N x /\left((N-1) E^{2}+x\right) \\
E & =\operatorname{Sqrt}[(N-n) x / n(N-1)
\end{aligned}
$$

1.5.6. Sampling technique

Simple Random Sampling

\subsubsection{Eligibility}

\subsubsection{Inclusion criteria}

- I have included only drivers who drive buses only.

- The bus drivers who drive bus, daily for atleast 10 hours.

- The bus drivers who have experience of at least one year of driving a bus

\subsubsection{Exclusion criteria}

- I exclude the bus drivers, who were experiencing any kind of systemic or chronic disease.

\subsubsection{Data collection}

The data collection procedures have been done by using a "standardized general Nordic questionnaire". [12] I collect data after an informed consent,(i.e.-I told about the aims and objectives of my study verbally to subject and I ensure the subjects for confidentiality) from subject and by giving questionnaire to bus drivers in Lahore, Pakistan. As this questionnaire is used to find out musculoskeletal symptoms so by this way, i collect data from bus drivers of Lahore, Pakistan about occupational musculoskeletal symptoms.

\subsubsection{Ethical consideration}

There were no ethical issues in this study

\subsubsection{Statistical procedure}

I use SPSS 17 version, software for data analysis. Categorical variables were measured using frequencies and discrete variables were measured by using mean and standard deviation, and as this is descriptive study, I use descriptive index test or frequency test or histogram test or box plot test.

\section{Results}

Table 1: Descriptive statistics for Age, experience and daily driving hours of Drivers

\begin{tabular}{|c|c|}
\hline & Mean \pm SD \\
\hline Age & $43.71 \pm 9.574$ \\
\hline Experience (Years) & $20.92 \pm 9.760$ \\
\hline Daily driving hours & $11.89 \pm 2.455$ \\
\hline
\end{tabular}

A total of 273 Nordic questionnaires were distributed among the truck drivers. All of the participants responded back. Mean \pm SD age of truck drivers was $43.71 \pm 9.574$ years. Experience in years and daily driving hours had Mean \pm SD of $20.92 \pm 9.760$ and $11.89 \pm 2.455$ respectively.

Table 2: Region wise frequencies of symptoms during last

\begin{tabular}{|l|c|c|}
\hline \multirow{2}{*}{ Region } & \multicolumn{2}{|c|}{$\begin{array}{c}\text { Any symptoms in last } 12 \text { months } \\
\text { (N=273) }\end{array}$} \\
\cline { 2 - 3 } & Yes & No \\
\hline Neck & $28(10.3 \%)$ & $245(89.7 \%)$ \\
\hline Shoulder & $91(33.3 \%)$ & $182(66.7 \%)$ \\
\hline Upper back & $45(16.5 \%)$ & $228(83.5 \%)$ \\
\hline Elbows & $7(2.6 \%)$ & $266(97.4 \%)$ \\
\hline Wrist/hands & $3(1.1 \%)$ & $270(98.9 \%)$ \\
\hline Lower back & $15(5.5 \%)$ & $258(94.5 \%)$ \\
\hline Hip/thigh & $15(5.5 \%)$ & $258(94.5 \%)$ \\
\hline Knees & $34(12.5 \%)$ & $239(87.5 \%)$ \\
\hline Ankle/foot & $15(5.5 \%)$ & $258(94.5 \%)$ \\
\hline
\end{tabular}




\section{International Journal of Science and Research (IJSR) \\ ISSN (Online): 2319-7064 \\ Index Copernicus Value (2013): 6.14 | Impact Factor (2015): 6.391}

During the last 12 months, most of the respondents had experienced symptoms in shoulder region(33.3\%) and $(66.7 \%)$ had no symptoms in shoulder region, followed by upper back symptoms $(16.5 \%)$ and $(83.5 \%)$ with no upper back symptoms, symptoms in knees region (12.5\%)and $(87.5 \%)$ with no symptoms in knees region, symptoms in neck region $(10.3 \%)$ and $(89.7 \%)$ with no symptoms in neck region, symptoms in hip/thighs and ankle/foot and lower back $(5.5 \%)$ with negative symptoms $(94.5 \%)$ in all above regions and followed by symptoms in elbows $(2.6 \%)$ and $(97.4 \%)$ had no symptoms in elbows, least number of participants (1.1\%) had experienced symptoms in wrist/hands region, with negative symptoms (98.9\%) during last 12 months.

Table 3: Descriptive statistics for difficulty in performing any activities, due to symptoms in last 12 months

\begin{tabular}{|c|c|c|}
\hline \multirow{2}{*}{ Region } & \multicolumn{2}{|c|}{$\begin{array}{c}\text { Difficulty in activities in last 12 } \\
\text { months }(\mathrm{N}=273)\end{array}$} \\
\cline { 2 - 3 } & Yes & No \\
\hline Neck & $10(3.7 \%)$ & $263(96.3 \%)$ \\
\hline Shoulder & $22(8.1 \%)$ & $251(91.9 \%)$ \\
\hline Upper back & $10(3.7 \%)$ & $263(96.3 \%)$ \\
\hline Elbows & $1(.4 \%)$ & $272(99.6 \%)$ \\
\hline Wrist/hands & 0 & $273(100 \%)$ \\
\hline Lower back & $15(5.5 \%)$ & $258(94.5 \%)$ \\
\hline Hip/thigh & $6(2.2 \%)$ & $267(97.8 \%)$ \\
\hline Knees & $12(4.4 \%)$ & $261(95.6 \%)$ \\
\hline Ankle/foot & $2(.7 \%)$ & $271(99.3 \%)$ \\
\hline
\end{tabular}

During the last 12 months, difficulty in performing any activities due to mostly symptoms in shoulder region( $8.1 \%)$ and $(91.9 \%)$ had no difficulty in performing any activities due to symptoms in shoulder region, followed by difficulty due to lower back symptoms $(5.5 \%)$ and $(94.5 \%)$ had no difficulty in performance of activities due to lower back region symptoms, difficulty due to knees symptoms $(4.4 \%)$ and $(95.6 \%)$ had no difficulty in performance of activities due to symptoms in knees, difficulty due to symptoms in neck and upper back regions (3.7\%)and $(96.3 \%)$ had no difficulty in performance of activities due to symptoms in neck and upper back regions, difficulty due to symptoms in hip/thigh region $(2.2 \%)$ and $(97.8 \%)$ had no difficulty in performance of activities due to symptoms in hip/thigh region, followed by difficulty due to symptoms in ankle/foot region $(0.7 \%)$ and $(99.3 \%)$ had no difficulty in performance of activities due to symptoms in ankle/foot region, difficulty due to symptoms in elbows region $(0.4 \%)$ and $(99.6 \%)$ had no difficulty in performance of activities due to symptoms in elbows region, 0 number of respondents with difficulty in performance of activities due to symptoms in wrist/hands region, during last 12 months.
Table 4: Descriptive statistics for "have you ever seen a physician for this condition, in last 12 months?'

\begin{tabular}{|c|c|c|}
\hline \multirow{2}{*}{ Region } & \multicolumn{2}{|c|}{$\begin{array}{c}\text { Seen A physician for this condition, in } \\
\text { last 12 months(N=273) }\end{array}$} \\
\cline { 2 - 3 } & Yes & No \\
\hline Neck & $12(4.4 \%)$ & $261(95.6 \%)$ \\
\hline Shoulder & $35(12.8 \%)$ & $238(87.2 \%)$ \\
\hline Upper back & $17(6.2 \%)$ & $256(93.8 \%)$ \\
\hline Elbows & $3(1.1 \%)$ & $270(98.9 \%)$ \\
\hline Wrist/hands & $2(0.7 \%)$ & $271(99.3 \%)$ \\
\hline Lower back & $17(6.2 \%)$ & $256(93.8 \%)$ \\
\hline Hip/thigh & $5(1.8 \%)$ & $268(98.2 \%)$ \\
\hline Knees & $14(5.1 \%)$ & $259(94.9 \%)$ \\
\hline Ankle/foot & $5(1.8 \%)$ & $268(98.2 \%)$ \\
\hline
\end{tabular}

During the last 12 months, most of the check-up`s from physician is due to symptoms in shoulder region(12.8\%) and (87.2\%) had never seen physician due to symptoms in shoulder region, followed by seen physician due to symptoms in upper back and lower back (6.2\%) and $(93.8 \%)$ had never seen physician due to symptoms in upper and lower back regions, seen physician due to symptoms in knees $(5.1 \%)$ and $(94.9 \%)$ had never seen physician due to symptoms in knees region, seen physician due to symptoms in neck region $(4.4 \%)$ and $(95.6 \%)$ had never seen physician due to symptoms in neck region, seen physician due to symptoms in hip/thighs and ankle/foot (1.8\%)and $(98.2 \%)$ had never seen physician due to symptoms in both regions and followed by seen physician due to symptoms in elbows $(1.1 \%)$ and $(98.9 \%)$ had never seen physician due to symptoms in elbows region, least number of participants seen physician $(0.7 \%)$ and $(99.3 \%)$ had never seen physician due to symptoms in wrist/hands region, during last 12 months.

Table 5: Descriptive statistics for "any trouble during last 7 days"

\begin{tabular}{|c|c|c|}
\hline \multirow{2}{*}{ Region } & \multicolumn{2}{|c|}{$\begin{array}{c}\text { Any trouble during last seven days } \\
(\mathrm{N}=273)\end{array}$} \\
\cline { 2 - 3 } & Yes & No \\
\hline Neck & $15(5.5 \%)$ & $258(94.5 \%)$ \\
\hline Shoulder & $59(21.6 \%)$ & $214(78.4 \%)$ \\
\hline Upper back & $34(12.5 \%)$ & $239(87.5 \%)$ \\
\hline Elbows & $3(1.1 \%)$ & $270(98.9 \%)$ \\
\hline Wrist/hands & $1(.4 \%)$ & $272(99.6 \%)$ \\
\hline Lower back & $25(9.2 \%)$ & $248(90.8 \%)$ \\
\hline Hip/thigh & $11(4 \%)$ & $262(96.0 \%)$ \\
\hline Knees & $22(8.1 \%)$ & $251(91.9 \%)$ \\
\hline Ankle/Foot & $10(3.7 \%)$ & $263(96.3 \%)$ \\
\hline
\end{tabular}

During the last 7 days, most of the respondents had experienced trouble in shoulder region $(21.6 \%)$ and $(78.4 \%)$ had no trouble in shoulder region, followed by upper back region $(12.5 \%)$ and $(87.5 \%)$ had no trouble in upper back region, followed by lower back region (9.2)and (90.8\%)had no trouble in lower back region, followed by knee`s region $(8.1 \%)$ and $(91.9 \%)$ had no trouble in knee`s region, followed by neck region $(5.5 \%)$ and $(94.5 \%)$ had no trouble in neck region, $(4 \%)$ had trouble in hip/thigh region and (96.0\%) had no trouble In hip/thigh region, (3.7\%) had trouble in ankle/foots region with no trouble in $(96.3 \%)$ respondents at ankle/foot region, (1.1\%) had trouble in elbows with no trouble in $(98.9 \%)$ respondents at elbows region, $(0.4 \%)$ had trouble in wrist/hands with no trouble in 


\section{International Journal of Science and Research (IJSR) \\ ISSN (Online): 2319-7064}

Index Copernicus Value (2013): 6.14 | Impact Factor (2015): 6.391

$(99.6 \%)$ respondents at wrist/hands region, during last 7 days.

\section{Conclusion}

Present study concludes that there is high frequency of job related musculoskeletal disorders common in bus drivers of Lahore, Pakistan. Most commonly effected regions were shoulder and upper back and least common was wrist/hands region.

\section{References}

[1] Szeto GP, Lam P. Work-related musculoskeletal disorders in urban bus drivers of Hong Kong. Journal of occupational rehabilitation. 2007;17(2):181-98. Epub 2007/02/03.

[2] Jensen A, Kaerlev L, Tüchsen F, Hannerz H, Dahl S, Nielsen PS, et al. Locomotor diseases among male long-haul truck drivers and other professional drivers. International archives of occupational and environmental health. 2008;81(7):821-7.

[3] Tamrin SBM, Yokoyama K, Jalaludin J, Aziz NA, Jemoin N, Nordin R, et al. The association between risk factors and low back pain among commercial vehicle drivers in peninsular Malaysia: a preliminary result. Industrial health. 2007;45(2):268-78.

[4] Robb MJ, Mansfield NJ. Self-reported musculoskeletal problems amongst professional truck drivers. Ergonomics. 2007;50(6):814-27.

[5] Okunribido OO, Shimbles SJ, Magnusson M, Pope M. City bus driving and low back pain: a study of the exposures to posture demands, manual materials handling and whole-body vibration. Applied Ergonomics. 2007;38(1):29-38.

[6] Bovenzi M, Rui F, Negro C, D’Agostin F, Angotzi G, Bianchi S, et al. An epidemiological study of low back pain in professional drivers. Journal of Sound and Vibration. 2006;298(3):514-39.

[7] Szeto GP, Lam P. Work-related musculoskeletal disorders in urban bus drivers of Hong Kong. Journal of occupational rehabilitation. 2007;17(2):181-98.

[8] Krause N, Ragland DR, Greiner BA, Syme L, Fisher JM. Psychosocial job factors associated with back and neck pain in public transit operators. Scandinavian journal of work, environment \& health. 1997:179-86.

[9] Akinpelu AO, Oyewole OO, Odole AC, Olukoya R. Prevalence of musculoskeletal pain and health seeking behaviour among occupational drivers in Ibadan, Nigeria. African Journal of Biomedical Research. 2013;14(2):89-94.

[10] Chen J-C, Dennerlein JT, Chang C-C, Chang W-R, Christiani DC. Seat inclination, use of lumbar support and low-back pain of taxi drivers. Scandinavian journal of work, environment \& health. 2005:258-65.

[11] Borle A, Gunjal S, Jadhao A, Ughade S, Humne A. Musculoskeletal morbidities among bus drivers in city of Central India. 2012.

[12] Kuorinka I, Jonsson B, Kilbom A, Vinterberg H, Biering-Sørensen F, Andersson G, et al. Standardised Nordic questionnaires for the analysis of musculoskeletal symptoms. Applied Ergonomics. 1987;18(3):233-7.

\section{Author Profile}

Muhammad WajahatAslam is Physical Therapist, Azra Naheed Medical College, Department of Physical Therapy, Main Raiwind Road,, Lahore

FahadTanveer is Lecturer, Azra Naheed Medical College, Department of Physical Therapy, Main Raiwind Road,, Lahore

Hafiz SherazArshad is Head of Department/Assistant Professor, Azra Naheed Medical College, Department of Physical Therapy, Main Raiwind Road,, Lahore

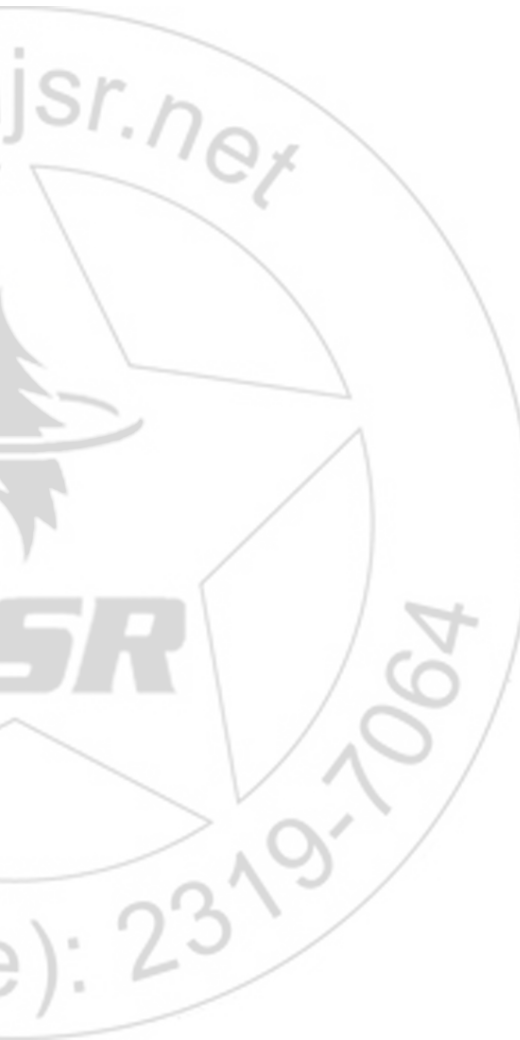

